\title{
A tribute to Emil Frei III
}

$\mathrm{D}$ . Emil Frei III, one of the fathers of combination chemotherapy for cancer, died after a prolonged illness in May of 2013. He was 89 years old (Figure 1).

Known to his colleagues, family, and friends as Tom, Frei was the emeritus director and emeritus physician-in-chief of the Dana-Farber Cancer Institute and the Richard and Susan Smith Distinguished Professor of Medicine emeritus at Harvard Medical School. A highly distinguished clinical investigator, Frei held leadership positions of major responsibility at the National Cancer Institute (NCI) in Bethesda, Maryland, and at the M.D. Anderson Cancer Center in Houston, Texas, before his appointment at Harvard.

Frei was born in St. Louis on February 21, 1924, where his paternal grandfather had founded Emil Frei and Associates, a wellknown stained glass company. He attended St. Louis University and then joined the United States Navy in World War II. The Navy sent him to Colgate University and then to Yale University for medical training. He graduated from Yale Medical School in 1948 and later served in the Navy Medical Corps during the Korean War.

In 1955, Frei and his close colleague Emil J. Freireich were recruited to the expanding clinical program at the NCI by Gordon Zubrod, then the newly appointed NCI clinical director. Supported by Zubrod's superb guidance and defense, Frei and Freireich began their controversial studies of the treatment of acute leukemia in childhood. This work revolutionized the management of that cruel disease and forever altered the medical treatment of cancer.

Modern cancer chemotherapy began with the studies of what turned out to be folate reductase inhibitors by Sidney Farber and his associates in the mid-1940s. At that time, children with acute leukemia died rapidly - half of any cohort expired in three months. Farber's use of a single agent, then aminopterin and later amethopterin, produced some complete remissions, but these were generally short-lived due to the development of resistance. (Later Fred Alt and his colleagues showed that resistance to folic acid reductase inhibitors was due to the emergence of leukemic cells with everincreasing levels of the enzyme.) Acknowledging the problem of resistance, Farber held that more effective drugs were needed

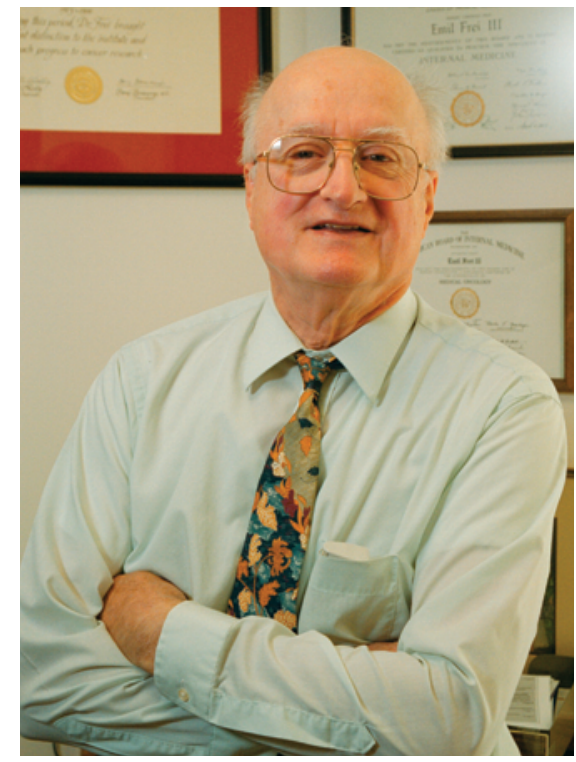

Figure 1

Emil Frei III.

that would attack different pathways. He believed that such drugs should be given sequentially to maintain remission after relapse occurred.

Farber's proposed use of sequential chemotherapy (assuming that new drugs could be found) was opposed by Abraham Goldin and Lloyd Law at the NCI as well as Howard Skipper and Frank Schabel at the Southern Research Institute in Alabama, who were experts in the drug treatment of leukemic cell lines and murine leukemia. They held that combinations of drugs with different targets given simultaneously provided the only hope for sustained remissions, since most cancers have infinite ways of finding their way around single agents. Zubrod, whose military medicine experience was in the malaria program of World War II, saw childhood leukemia as the cancer equivalent of malaria and agreed with the basic scientists. He urged Frei and Freireich to combine drugs as they were produced to treat leukemia in childhood, to collaborate with other like-minded physicians, and to train younger physicians to learn the new paradigm of cancer chemotherapy on the wards of the NCI. Frei committed himself to decades of effort and ultimately was highly successful in all of these endeavors. The development of the VAMP program (a combination of vincristine, amethopterin, 6-mercaptopurine, and prednisone) led to long-term remissions and many cures. The later addition of more agents, such as adriamycin and asparaginase, has brought the cure rate of childhood leukemia close

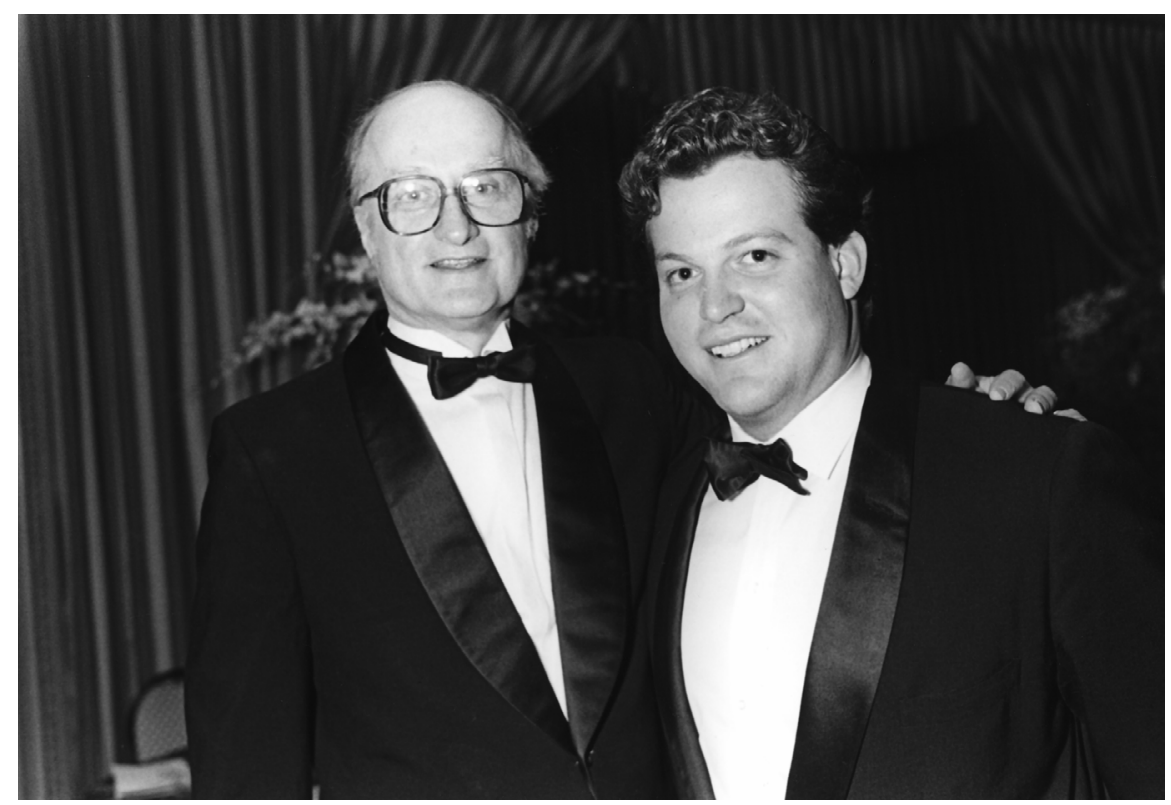

Figure 2

Emil Frei III with Edward M. Kennedy Jr. 
to $90 \%$. Frei's collaborative and training efforts are best demonstrated by the highly unusual results of the Lasker Prize deliberations in 1972. In 1966, only Sidney Farber received a Lasker Prize in clinical medicine. In 1972, no less than 16 pioneers of effective combination cancer therapy were so honored. Among them were Zubrod, Frei, and Freireich and several of their trainees and collaborators.

Frei remained at the NCI for over a decade. Among his many accomplishments there was the training of Vincent DeVita, who initiated successful studies of combination chemotherapy in Hodgkin disease and, with George Canellos, developed an important adjuvant combination chemotherapy program for breast cancer. Frei then moved with Freireich to the M.D. Anderson Cancer Center before he assumed his leadership of cancer medicine at Harvard and the Dana-Farber Cancer Institute in 1972. He remained in those posts until he retired.

At Dana-Farber, Frei built a strong basic cancer biology program, massively expanded biostatistics and clinical trial expertise, recruited and trained excellent young clinical scientists, created a renowned cancer immunology program, and greatly strengthened the Dana-Farber leukemia and breast cancer programs. He resumed his interest in pediatric oncology and contributed to the development of Stephen Sallan as an international leader of clinical trials in acute childhood leukemia. He launched DanaFarber and Boston Children's Hospital into a concerted effort to manage osteosarcoma. His most famous osteosarcoma patient, Edward M. Kennedy Jr., was recently quoted as saying, "I honestly believe that Dr. Frei saved my life" (ref. 1; Figure 2).
Frei's encyclopedic knowledge of cancer chemotherapy made him an invaluable teacher. His textbook, Cancer Medicine, became the leading book of its kind in the United States. With all of that prestige, Tom Frei was forever down-to-earth, optimistic, supportive, kind, and generous. He is sorely missed, but his impact on cancer treatment will remain with us for many years.

\section{Edward J. Benz Jr.}

Dana-Farber Cancer Institute, Harvard Medical School, Boston, Massachusetts, USA. E-mail: edward_benz@dfci.harvard.edu.

\section{David G. Nathan}

Dana-Farber Cancer Institute, Harvard Medical School, Massachusetts, USA. E-mail: David_Nathan@dfci.harvard.edu.

1. Fox M. Emil Frei III, who put cancer cures in reach, dies at 89. New York Times. May 5, 2013:A24. 